\title{
Validation of Commonly Used Rectangular Nitinol Archwire Dimensions Using Stereomicroscope - An Invitro Study.
}

Vasu Murthy $\mathrm{S}^{1}$, Pavan Kumar $\mathrm{M}^{2}$, Praveen Kumar $\mathrm{N}^{3}$, Shiva Prasad $\mathrm{M}^{4}$, Sreekanth $\mathrm{K}^{5}$, Samatha Reddy $\mathrm{V}^{6}$

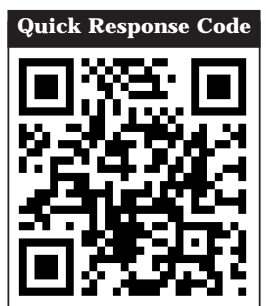

doi: $10.5866 / 2017.9 .10077$

${ }^{1}$ Professor \& HOD

${ }^{2}$ Professor

${ }^{3}$ Reader

$4 \& 5$ Senior Lecturer

${ }^{6}$ Post Graduate Student

Department of Orthodontics

Kamineni Institute of Dental Sciences

Sreepuram, Narketpally, Nalgonda (Dt)

\section{Article Info:}

Received: April 8, 2017

Review Completed: May 10, 2017

Accepted: J une 11, 2017

Available Online: J une, 2017 (www.nacd.in)

(c) NAD, 2017 - All rights reserved

\section{Email for correspondence:}

vasuortho@gmail.com

\section{ABSTRACT:}

Context/Background: Achieving a satisfactory inclination or torque of the incisors is important for the final esthetic result. Torque expression depends upon a number of factors including the size of the bracket slots and archwires. Use of undersized archwires may directly and adversely affect the three dimensional tooth positioning.

Aims \& Objectives: Objectives of the present study were to measure the dimensions of Nitinol archwires $(0.017 \times 0.025 "$, $0.019 \times 0.025$ ") of three different companies

Methods: 10 Nitinol archwires of each 0.017"x0.025", 0.019 "x0.025" dimensions from three different companies (Modern Orthodontics, Prime orthodontics and Captain Orthodontics) were taken for the study. Stereomicroscope (Magnus MSZ-Bi) was used for measurement of archwire dimensions (height and width) and calibrated using I mage Pro insight Software.

Results: The values obtained were compared to the dimensions published by each manufacturer. Comparisons were also made between wires of different manufacturers. The values obtained were subjected to multiple comparisons (Post Hoc Tests) of height and width of archwires.

Conclusion: It can be concluded that the archwire measured dimensions were different than stated by the manufacturers. Among the dimensions of three manufacturers, Modern Orthodontics was close to the standard values. The dimensions of Prime Orthodontics and Captain Orthodontics archwires wereless than the standard values

Key words: Nitinol Archwires, Height and width of archwires, Stereomicroscope.

\section{INTRODUCTION}

Orthodontic archwires are essential components of modern fixed appliances. The brackets used nowadays are of Pre-adjusted Edgewise appliance. The placing of maximum prescription archwires in a pre-adjusted bracket is designed to produce threedimensional tooth moving forces. These forces are 
created as a result of intimate fit of the wire into the bracket slot and any 'play' or 'slop' between these components will result in incomplete transmission of the bracket prescription to the tooth and its supporting tissues. Use of undersized archwires may directly and adversely affect the three dimensional tooth positioning. ${ }^{1}$

Achieving a satisfactory inclination or torque of the incisors is important for the final esthetic result. Torque expression depends upon a number of factors including the size of the bracket slots and archwires. Full torque expression should potentially be achieved by using an archwire of the appropriate size to fill the bracket slot; however, to insert a full size rectangular archwire it is necessary that there is a certain amount of 'play'. This means that the vertical dimension or height of the bracket sl ot must be greater than the height of the archwire. If there is a larger discrepancy between the bracket sl ot and the archwire dimension, then there will be inconsistencies in the amount of torque expressed. ${ }^{2}$

Siatkowski illustrated that there is loss of anterior torque with use of undersize archwires. ${ }^{3}$ Kusy and Whitley stated that variations in archwire dimensions may account for failure of protraction mechanics, as well as for the loss of incisor axial inclination control during other forms of tooth movement. ${ }^{4}$ Hence it is of utmost importance that the wires be precisely manufactured to have correct prescription.

The purpose of the present study carried out in the Department of Orthodontics and Dentofacial Orthopaedics at Kamineni Institute of Dental Sciences, $\mathrm{N}$ al gonda is to validate the dimensions of rectangular nitinol archwires and, if any, between reported and actual dimensions

\section{Materials and Methods:}

\section{Materials:}

The materials used for the study:

- 10 nitinol archwires of each $0.017^{\wedge} \times 0.025^{\wedge}$, $0.019^{\wedge} \times 0.025^{\wedge}$ dimensions from three different companies (Modern Orthodontics, Prime orthodontics and Captain Orthodontics) weretaken for the study.

- $\quad$ Stereomicroscope (Magnus MSZ-Bi) was used for measurement of archwire dimensions (Figure 1).

\section{Methodology:}

The selected wires were viewed under a stereomicroscope at $4 x$ magnification. Each selected wire was scanned and captured individual ly by using stereomicroscope to produce a digital image. The images were exported and calibrated using I mage Pro insight Software and height and width of wires were measured (Figure 2).

The values obtained were compared to the dimensions published by each manufacturer. Comparisons were also made between wires of different manufacturers.

\section{RESULTS:}

The values obtained were subjected to statistical analysis by using SPSS version 22.0 software. The values obtained were subjected to multiple comparisons (Post Hoc Tests) of height and width of archwires and have been tabulated (Tables 1-5).

\section{DISCUSSION}

Standardization is an essential tool requirement for technological progress. Edward $\mathrm{H}$ Angle introduced Edgewise bracket of 0.022 inch as the standard slot size for brackets. The 0.022 inch system offers more options in archwire size selection. With the use of undersized archwire, one can facilitate the free sliding of archwire through the bracket slot. Being able to use larger diameter archwires for treatment provides increase stiffness and allows to keep the teeth upright during space closure with different retraction mechanics. Use of undersized archwires may directly and adversely affect the three dimensional tooth positioning.

The play between the archwire and bracket slot is of fundamental importance in clinical orthodontics, as it indicates how many degrees the archwire must be rotated within the bracket before its edges come into contact with the slot walls, enabling it thus to transmit third-order information 


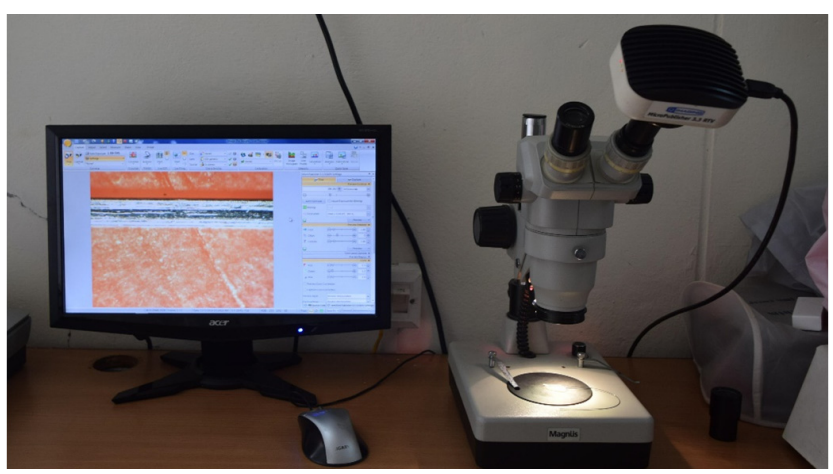

Figure 1: Archwire seen under Stereomicroscope and subjected for analysis.

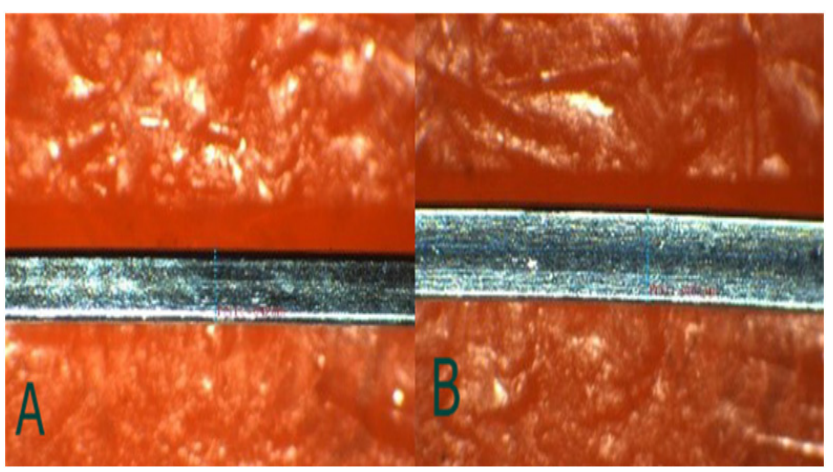

Figure 2: Photographs of archwire height and width dimensions (A. Height and B. Width)

Table 1: Depicts mean, standard deviation and level of significance ( $p$-value) of $0.017 \times 0.025 \mathrm{Nitinol}$ wires between three different companies.

\begin{tabular}{lllrr}
\multirow{2}{*}{ Height } & COMPANY & MEAN & SD & P-value \\
\cline { 2 - 5 } & Modern Orthodontics & 0.386 & 0.006 & 0.000 \\
\cline { 2 - 4 } & Prime Orthodontics & 0.371 & 0.005 & \\
\cline { 2 - 4 } Width & Captain Orthodontics & 0.378 & 0.006 & 0.05 \\
& Modern Orthodontics & 0.557 & 0.004 & \\
\cline { 2 - 4 } & Prime Orthodontics & 0.544 & 0.0066 & \\
\cline { 2 - 5 } & Captain Orthodontics & 0.553 & 0.004 & \\
\hline
\end{tabular}

Table 2: Multiple comparison (Post Hoc Tests)

- Height

\begin{tabular}{lll} 
COMPANY & & P - Value \\
Modern Ortho & Prime Ortho & 0.000 \\
& Captain Ortho & 0.027 \\
\hline Prime Ortho & Modern Ortho & 0.00284 \\
& Captain Ortho & 0.0028 \\
\hline Captain Ortho & Modern Ortho & 0.008 \\
Prime Ortho & & 0.007 \\
\hline
\end{tabular}

Table 3: Multiple comparison (Post Hoc Tests) - Width

\begin{tabular}{lll} 
COMPANY & & P - Value \\
Modern Ortho & Prime Ortho & 0.000 \\
& Captain Ortho & 0.374 \\
\hline Prime Ortho & Modern Ortho & 0.000 \\
& Captain Ortho & 0.000 \\
\hline Captain Ortho & Modern Ortho & 0.374 \\
Prime Ortho & & 0.000 \\
\hline
\end{tabular}

Table 4: Depicts mean, SD and p-value of $0.019 \times 0.025$ Nitinol wires between three different companies.

\begin{tabular}{llrrr} 
& COMPANY & MEAN & SD & P-value \\
\multirow{3}{*}{ Height } & Modern Ortho & 0.426 & 0.0078 & 0.001 \\
\cline { 2 - 5 } & Prime Ortho & 0.423 & 0.008 & \\
\cline { 2 - 4 } Width & Captain Ortho & 0.417 & 0.006 & \\
\cline { 2 - 4 } & Modern Ortho & 0.55 & 0.0086 & 0.527 \\
\cline { 2 - 4 } & Prime Ortho & 0.545 & 0.00666 \\
& Captain Ortho & 0.548 & 0.0066 & \\
\hline
\end{tabular}



Table 5: Multiple comparison (Post Hoc Tests)
- Height

\begin{tabular}{lll} 
COMPANY & & P - Value \\
Modern Ortho & Prime Ortho & 0.558 \\
& Captain Ortho & 0.001 \\
\hline Prime Ortho & Modern Ortho & 0.558 \\
& Captain Ortho & 0.034 \\
\hline Captain Ortho & Modern Ortho & 0.001 \\
Prime Ortho & & 0.034 \\
\hline
\end{tabular}

to the tooth. The degree of play depends entirely on geometric parameters, namely the real slot height, the dimensions of the archwire and the beveling of its edge. However, on the products on the market, these do not always conform to the measurements declared by the manufacturer. ${ }^{2}$

Siatkowski noted that maxillary and mandibular incisors may suffer unexpected loss of torque while using smaller-dimension rectangular wires or when inadvertently using undersized maximum-prescription archwires or wires with an excessive edge bevel. ${ }^{3}$

Helge Fischer-Brandies et al conducted a study to investigate the influence of cross section, edge geometry and structural hardness on torque transmission between square wire and bracket. They found that as a result of excessively small wire dimensions and plastic deformation of the brackets, a relatively large torque play occurs. ${ }^{5}$

I osif Sifakakis et al compared the archwires inserted during the final stages of the orthodontic treatment with the generated moments at 0.018and 0.022 -inch brackets. The same prescription bracket type, was evaluated in both $0.017 \times 0.025$ and $0.019 \times 0.025$ dimensions with TMA and stainless steel wires. This difference is exaggerated in steel archwires, in comparison with the TMA, because of differences in stiffness. The differences of maximum moments between the archwires of the same crosssection but different alloys were statistically significant at both slot dimensions. ${ }^{6}$

Luca Lombardo et al evaluated the degree to which the height, width, and cross-section of rectangular and square orthodontic archwires affect the play between thearchwires and the bracket slot. The curvature (radius) of the edge bevels was also measured to calculate the play within the slot, and this measurement was compared with the ideal value. They found that the real height and width of the archwires differed from those stated by the manufacturers. ${ }^{7}$

The present study was done to compare the archwire dimensions between three different companies (Modern Orthodontics, Prime orthodontics and Captain Orthodontics and compare the dimensions with the standard value published by the manufacturer.

When $0.017 \times 0.025 \mathrm{NiTi}$ wires were compared between three companies the results showed a statistical significant difference in terms of height of the archwire $(p=0.000)$ indicating that the height of the archwires were different among all three companies (Table 1 and 2).

In terms of width of the archwire the results were insignificant indicating that all three brands are similar among themselves in terms of width of the archwire (Table 1 and 3).

When $0.019 \times 0.025 \mathrm{NiTi}$ wires were compared between three companies the results showed a statistical significant difference in terms of height of the archwire $(p=0.000)$ indicating that the height of the archwires were different among all three companies (Table 4 and 5).

In terms of width of the archwire the results were insignificant indicating that all three brands are similar among themselves in terms of width of the archwire (Table 3 and 4).

When $0.017 \times 0.025 \mathrm{NiTi}$ wires were compared to its standard value $(0.431 \mathrm{~mm}, 0.0635 \mathrm{~mm})$, all are undersized but M odern Orthodontics company wires showed dimensions close to that of standard value prescribed by manufacturer.

When $0.019 \times 0.025 \mathrm{NiTi}$ wires were compared to its standard value $(0.482 \mathrm{~mm}, 0.0635 \mathrm{~mm})$, all are undersized but M odern Orthodontics company wires showed dimensions close to that of standard value 
prescribed by manufacturer.

\section{Conclusion}

The results of this study pointed to the following conclusions:

1. The archwire dimensions were different than stated by the manufacturers.

2. The dimensions of Modern Orthodontics were close to the standard values.

3. The dimensions of Prime Orthodontics and Captain Orthodontics archwires were less than the standard values.

\section{REFERENCES}

1. Karan Tangri, Piush kumar, Payal sharma, Kiran kumar. A Comparison of the Accuracy of 0.022 Slots at Face, Base and Mesial and Distal Surface of Brackets marketed by Different Manufacturers. J Ind Orthod Soc 2012; 46(3):132-6.

2. J och A, Pichelmayer M, Weiland F. Bracket slot and archwire dimensions: manufacturing precision and third order clearance. J Orthod 2010; 37:241-9.
3. Raymond. E. Siatkowski. Loss of anterior torque control due to variations in bracket slot and archwire dimensions J Clin Orthod 1999; 33(9):508-10.

4. Kusy RP, Whitley J Q. Assessment of second-order clearances between orthodontic archwires and bracket slot via the critical contact angle for binding Angle Orthod 1999; 69(1):71-80.

5. Fischer-Brandies, Es-Souni M, Meyer. Torquetransmission between square wire and bracket as a function of measurement, form and hardness parameters. J Orofac Orthop 2000; 61(4):258-64.

6. Sifakakis I, Pandis N, Makou M, Eliades T, Katsaros C, Bourauel $C$. Torque efficiency of different archwires in 0.018 and 0.022 inch conventional brackets. Angle Orthod 2014; 84(1):149-54.

7. Lombardo L, Arreghini A, Bratti E, Mollica F, Spedicato G, Merlin $M$ et al. Comparative analysis of real and ideal wireslot play in square and rectangular archwires. Angle Orthod 2015; 85(5):848-58.

\section{Gain quick access to our journal online View our journal at www.nacd.in}

